\title{
O CUIDADO DE SI NO CONTEXTO DA EDUCAÇÃO ESPECIAL
}

\author{
Joseli Maria Jofre ${ }^{1}$
}

\section{Introdução}

De acordo com as Diretrizes Curriculares da Educação Especial do Estado do Paraná (BRASIL, 2006) a Educação Especial é uma modalidade de ensino que possui os mesmos princípios da Educação Básica. Porém, tal posicionamento demanda atenção e diálogo entre toda a sociedade envolvida para que o aluno com necessidades educacionais especiais seja atendido em sua amplitude.

São considerados alunos com necessidades educacionais especiais todos aqueles com deficiência, transtornos globais do desenvolvimento, transtornos funcionais específicos e altas habilidades/superdotação. O artigo $\mathrm{n}^{\circ}$. 205 da Constituição Federal (1988) retrata os princípios da Educação, ao caracterizá-la como direito de todos e dever do Estado e da família, promovida e incentivada com a colaboração da sociedade, visando ao pleno desenvolvimento da pessoa, seu preparo para o exercício da cidadania e sua qualificação para o trabalho (BRASIL, 1988).

Assim como direito de todos, a educação deve atingir a diversidade, deve sempre acreditar no potencial humano, e acreditar que o aluno que possui deficiência intelectual pode ser sujeito transformador de sua realidade e assim fazer uso do conhecimento para melhorar sua qualidade de vida ao colocar em prática sua cidadania.

Para que tal conhecimento se efetive e o desafio da participação e aprendizagem dos alunos especiais seja vencido, faz-se imprescindível a prática da formação docente continuada de professores que atuam nas escolas especiais e, também, em escolas comuns.

Tal capacitação profissional diz respeito ao aprimoramento pedagógico, por meio de estudos específicos sobre as características e singularidades educacionais dessa demanda, a partir desses aprimoramentos será possível à flexibilização e adequação dos objetivos propostos, a utilização de metodologias pertinentes ao ensino de determinado conteúdo, o uso de tecnologias assistivas e recursos humanos, manuseio de materiais específicos, na adequação do tempo e reorganização do espaço para que esses alunos efetivem seu direito de aprender.

O objetivo desse trabalho se constitui em: refletir sobre as atribuições da formação pedagógica direcionada à Educação Especial; dialogar tais reflexões com o conceito de "cuidado de si" apresentado na obra A hermenêutica do sujeito de Michel Foucault (2006); analisar diante desse exposto se o aluno se configura como o sujeito que cuida de si à medida que desenvolve habilidades, independência e autonomia, e se é o professor o mediador que vai direcioná-lo para essas ações.

\section{Fundamentação teórica}

Como fundamentação teórica para esse trabalho, serão utilizadas as ideias presentes no livro de Michel Foucault, um filósofo francês que embora não tenha focado suas pesquisas especificamente na área da Educação, nas aulas de A hermenêutica do sujeito (FOUCAULT, 2006), por meio de uma interpretação arqueológica do "cuidado de si", permite que se estabeleça essa relação.

\footnotetext{
${ }^{1}$ Especialista em Educação Especial (ASSESPI-UCP, 2008). Professora da SEED - em exercício na APAE Abatiá-PR. E-mail: jomjofre@gmail.com.
} 
$\mathrm{Na}$ modalidade de educação especial, por exemplo, existe sempre uma verdadeira preocupação com as relações sociais, até porque se trata de um processo de inclusão que precisa beneficiar esse público alvo, literalmente isolado pela sociedade.

Foucault, ao ministrar tal curso, resultado de suas pesquisas, demonstra que, na cultura antiga, é possível analisar o cuidado de si sob diferentes enfoques e relacioná-lo ao conhecimento de si. Para ele, "em todo o seu esplendor e em toda a sua plenitude: o cuidado de si deve consistir no conhecimento de si" (FOUCAULT, 2006, p. 85).

Assim, é de extrema importância que as pessoas que possuem algum tipo de deficiência, seja: intelectual; auditiva; visual ou múltiplas, possam conhecer as limitações que possuem, até para que possam se relacionar de uma maneira mais intensa com essas dificuldades, um trabalho para os profissionais da educação que atuam diretamente com essas pessoas, e possuem além do papel fundamental de ensinar o papel de mediação desse autoconhecimento para aprimoramento da autoestima, senso de superação e independência inclusive nas tarefas básicas da vida diária, como cuidar da aparência e da higiene.

É fundamental que se faça uma análise, em relação ao modo como são oferecidas as estratégias para os alunos que possuem algum tipo de deficiência, se as mesmas realmente demonstram algum grau de proficiência, para ir de encontro às necessidades que cada um dos alunos venha a apresentar.

Também serão utilizados referenciais que tratam do processo de inclusão de alunos com necessidades educacionais especiais no ensino regular, como forma de situar o contexto e as dificuldades apresentadas nesse processo de mediação do outro em busca do conhecimento e emancipação humana.

De acordo com Rodrigues (2006, p. 302):

A educação inclusiva dispõe sobre as políticas, as culturas e as práticas que contribuem sobre a formação ativa do aluno, ao torná-lo sujeito capaz de objetivos e direitos no ato educativo, e que possam se relacionar de uma maneira mais qualificada com a sociedade de uma maneira geral.

Ainda existe muito preconceito contra as pessoas que possuem algum tipo de necessidade especial. Por essa razão, as escolas especiais possuem uma relevância muito grande para a formação de uma sociedade que saiba contemplar as necessidades desse público específico.

Alvo de muita polêmica no meio educacional, a política de inclusão já passou por momentos distintos em nossa sociedade, as Diretrizes Curriculares da Educação Especial do Estado do Paraná (2006), menciona que existe ao menos três tendências sobre a forma de pensar e praticar a inclusão nos sistemas educacionais, que se diferenciam em natureza, princípios e formas de realizá-la em sala de aula.

A primeira, conhecida como inclusão condicional, é a mais conservadora, onde seus defensores a apoiam desde que, as escolas estejam devidamente adaptadas, os professores sejam previamente capacitados ou se diminuírem o número de alunos turma. Todas essas questões são importantes, e deviam se fazer presente no processo escolar desde o início.

Trabalhar com um número elevado de alunos com necessidades especiais é um grande risco, principalmente para o educador, que não conseguirá realizar um trabalho mais qualificado, até porque existe a necessidade de haver um atendimento educacional especializado para cada um.

Segundo Carvalho (2007), a educação inclusiva defende uma escola aberta a todos, uma vez que nossa sociedade é plural e democrática, assim deve oferecer subsídios e iguais 
oportunidades para que os alunos ingressem, permaneçam e, principalmente, participem do processo de aprendizagem, para ser construtores do seu próprio conhecimento.

A segunda tendência, inclusão total ou radical, defende inclusão irrestrita de todos os alunos no ensino regular, propõe realizar as adaptações para se adequar às particularidades na medida do possível.

No entanto, esse é um avanço que esse encontra ainda muito distante de acontecer, uma vez que, as escolas regulares há muito demonstram que não existem condições de receber alunos com níveis de deficiência mais elevados, e que por essa razão, exigem uma quantidade maior de recursos, e de conhecimento por parte dos educadores (GADOTTI, 2007).

Em outras palavras, o processo de inclusão nas escolas regulares já possui algumas décadas, visa permitir que as pessoas com diferentes níveis de deficiência tenham condições de viverem em sociedade, essa é uma questão que também necessita ser debatida com maior intensidade.

Já a terceira tendência abordada no documento, diz respeito à inclusão responsável, como o desafio de repensar e reestruturar políticas educativas, para criar oportunidades de acesso para alunos com necessidades educacionais especiais para que os mesmos tenham acesso e permanência na escola.

Ao levar em consideração as necessidades que as pessoas com deficiência possuem, existe a necessidade de uma grande transformação para que as escolas regulares possam ser mais ativas no sentido de incluir os educandos com deficiência (MAZZOTA, 1996).

De qualquer modo, é preciso levar em conta a pouca estrutura que a grande maioria das escolas regulares apresenta, e que nem sempre consegue beneficiar os seus próprios alunos considerados comuns, que apresentam necessidades menores que os demais.

Dessa forma, Mantoan (2015, p. 28) propõe que todo o sistema de ensino deve ser estruturado de forma a tornar-se um sistema de inclusão que considera as necessidades especiais e se adequa a elas. Assim, incluir é mais que acessibilidade arquitetônica, é mais que inserir alunos especiais no ensino regular, é efetivar e potencializar seu desenvolvimento como ser humano, capaz de transpor barreiras para se situar como sujeito de direitos e deveres.

Em geral, essa proposta de escolarização busca atender as especificidades dos estudantes com deficiência, ao perceber em sua singularidade a amplitude de possibilidades em sua formação, ao percebê-lo de maneira global, ao dar ênfase em suas capacidades e não apenas em suas limitações. Visto a possibilidade de transformar suas realidades com maior independência e empoderamento.

O processo de inclusão é trabalhado de maneira muito mais abrangente por parte das escolas especiais, assim os educandos considerados especiais precisam muito dessa modalidade educacional para terem uma chance real de serem incluídos na sociedade de maneira mais qualificada (BRASIL, 2000).

De uma maneira geral, é preciso destacar como as escolas preocupadas com a inclusão responsável devem possuir uma estrutura mais enriquecedora do que todas as demais modalidades educacionais, com isso, são capazes de beneficiar concretamente as pessoas com deficiência.

Respostas educativas que devem ser dadas pelo sistema educacional, de forma a favorecer a todos os alunos e dentre estes, os que apresentam necessidades educacionais especiais: a) de acesso ao currículo; b) de participação integral, efetiva e bem-sucedida em uma programação escolar tão comum quanto possível. (BRASIL, 2000, p. 7).

Segundo Sassaki (2010), o processo pelo qual uma pessoa, ou um grupo de pessoas, usa o seu poder pessoal para fazer escolhas e tomar decisões é visto como empoderar. É possível utilizar o termo "empoderar", adequando-o à temática do cuidado de si como instrumento capaz de transformar seu dia a dia e melhorar sua qualidade de vida. 


\section{Procedimento metodológico}

Conforme Minayo (1994), as questões sociais são historicamente objeto de estudo, devido às especificidades das sociedades humanas em determinado espaço, numa dialética constante do que já foi construído e o que ainda está por vir nas pesquisas sociais. Essas pesquisas trazem a relação entre sujeito e objeto pois lida diretamente com seres humanos e os vincula a visões de mundo, interesses e conhecimentos historicamente construídos.

Assim, o objeto das Ciências Sociais é essencialmente qualitativo. O método de abordagem para elaboração deste trabalho, quanto aos procedimentos técnicos, se caracterizou como uma pesquisa teórica, realizada por meio de bibliografia pertinente. Após terem sido realizadas diversas pesquisas em obras de autores renomados e que muito contribuíram com o desenvolvimento do tema proposto, para que o artigo obtenha a densidade necessária, para que possa servir de suporte para estudos futuros.

Segundo Marconie Lakatos (2011), a pesquisa bibliográfica é o levantamento das pesquisas e publicações realizadas anteriormente sobre o tema. Com a finalidade de colocar o pesquisador frente ao que já se sabe sobre o assunto. Dessa forma, o trabalho buscou estabelecer um diálogo entre o papel do professor, seu aperfeiçoamento profissional, as necessidades educacionais especiais e o significado do cuidado de si, resgatado desde a antiguidade grega.

A pesquisa é fundamental para que uma quantidade mais elevada e apurada de informações dialogue com o tema, e que tem como meta promover uma culturalização maior do presente objeto, para poder agregar valores aos leitores do presente artigo, já que veremos que o processo de inclusão já possui alguns anos, porém continua a fomentar visões antagônicas a respeito dessa temática, que se configura como realidade em ambientes escolares no Brasil e no mundo.

\section{Reflexões sobre o cuidado do outro no processo de inclusão}

A sociedade vê a escola como um possível espaço de transformação, onde acontece a mudança de vida, de crenças, de atitudes de professores, alunos e comunidade escolar, com inúmeros projetos sociais que estão se deslocando a esse espaço e configuram mudanças significativas nos ambientes escolares, porém, essas características trazem à educação um viés assistencialista. Apostar nas escolas como lugares educativos, capazes de favorecer o desenvolvimento de sujeitos esclarecidos, críticos e autônomos ainda é, ou deveria ser, a grande missão da educação nacional. Assim, é fundamental acrescentar nessa perspectiva o sentimento e a aprendizagem voltada para o respeito às diferenças e a diversidade como um todo.

Nesse sentido, recorre-se a Mantoan (2006), que diz que a escola deve ser plural, deve aceitar a inclusão incondicional, pois assim, ao crescer no convívio com as diferenças em sala de aula, naturalmente o aluno se tornará um sujeito capaz de respeitar toda e qualquer diversidade, e assim praticar a inclusão sem tanto esforço como ainda ocorre atualmente.

$\mathrm{O}$ aspecto do Cuidado de Si de Foucault (1982) traz a figura do mediador, que nesse processo de inclusão de quem apresenta necessidades especiais, tem que ser visto como o professor especialista em Educação Especial. Essa perspectiva traz à luz a importância da formação e da construção dos saberes necessários para bem atuar nesse processo inclusivo, o termo formação faz referência não apenas à formação inicial que é obrigatória para ingresso no cargo de professor, e sim à formação continuada, onde continuamente o professor possa estudar e se atualizar, para melhor desempenhar a importante tarefa de mediar os processos educativos e relacionais dentro da escola. Sem que se atenda à necessidade de uma formação voltada para a realidade de cada escola, dificilmente os problemas educacionais serão sanados. 
Pensar um aperfeiçoamento pedagógico em nível de país ou Estados Federativos, desvaloriza e desrespeita a singularidade de cada ambiente escolar, onde os problemas, as dificuldades, e a realidade não são iguais. Visto que tanto o processo inclusivo com a auto identificação do aluno deficiente como sujeito capaz de se conhecer para superar dificuldades passa pelas mãos e olhar do professor, o que justifica assim sua necessidade de aperfeiçoamento através de formação continuada.

\section{Conclusão}

Ao retornar à trajetória dessa breve pesquisa, é importante relembrar sua finalidade de incluir dentro do contexto da Educação Especial um recorte específico do cuidado de si, mais precisamente do cuidado de si no sentido de conhecer-se.

Como relatado por Foucault (1982), o filósofo Sócrates evidenciava a necessidade de incitar o "cuidado de si" no outro. Assim as formações pedagógicas e continuadas se mostraram fundamentais nesse processo, pois o professor não carrega características inatas, de possuir o olhar voltado para a necessidade especial de cada aluno, essas competências são adquiridas através do processo de formação, assim como em outras profissões, como a de médico, engenheiro ou administrador, o profissional necessita de capacitação continuamente.

Durante a aula do dia vinte e sete de janeiro (1982), a questão do "outro" é fortemente abordada, posiciona o outro "ser" como mediador na constituição da prática de si, ou seja, para que o cuidado de si aconteça é necessária à existência de outra pessoa de forma indispensável, a essa prática do outro, que faz a mediação para que a prática de si se desenvolva numa segunda pessoa, é dado o nome de "mestria".

A mestria foi definida de três formas: a primeira, a mestria do exemplo possibilita que o jovem tenha uma referência, como no caso dos heróis e anciãos, onde o jovem pode memorizar um modelo. A segunda, a mestria da competência, trata da transmissão do conhecimento aos mais jovens. Por fim a terceira, a mestria socrática que se configura através de diálogo e questionamentos, onde o saber se origina a partir da própria ignorância, mas sempre necessitará de um movimento que depende do outro.

A partir do exposto acima, é possível caracterizar o professor como aquele que faz a mediação e auxilia o aluno em seu autoconhecimento e aprendizagem, bem como, a formação continuada, onde pesquisadores e estudiosos podem ser os mediadores que auxiliam os professores em eventuais necessidades para o ofício de sua profissão.

Como referendado na mesma obra, a ideia de correção pode ser analisada com o retorno a Sêneca, ao resgatar o conceito de stultitia, que se configura como o avesso do cuidado de si, o stultus é o que não pratica o cuidado de si, e também não possui vontades verdadeiras, já que a vontade para ser absoluta tem que vir do cuidado de si na relação consigo.

A forma para sair desse estado de stultitia depende da intervenção do outro, esse outro que deverá intervir, no entanto, não será um transmissor de saber ou habilidade, mas aquele que estenderá a mão, para tirá-lo desse abismo pessoal, o outro se apresenta na figura do filósofo.

Assim todo "ser" necessita do outro em seu processo educacional e saída da stultitia, que pode ser relacionada aqui com a falta de conhecimento. Claramente que o professor não pode ser visto como o dono da verdade, e sim como aquele que busca e aperfeiçoa seus conhecimentos constantemente na intenção de mediar o conhecimento de si por parte da pessoa com necessidade educacional especial, ao ajudá-la, prepará-la, direcioná-la ao processo de inclusão social, para o desenvolvimento de sua autonomia e independência.

Essas pontuações firmam sua importância já que na Educação Especial é possível ver o cuidado de si refletido principalmente no conhecimento de si, visto que crianças e adultos com 
necessidades especiais tem como forte característica a dificuldade de relacionamento interpessoal, e ao conhecer-se e se verem como sujeitos de sua vida, podem estabelecer relações ao superar-se no que for possível; aceitar-se; e aprenderem a arte de viver consigo frente as suas características físicas, intelectuais e emocionais.

\section{Referências}

BRASIL. Constituição da República Federativa do Brasil. Brasília, DF: Senado Federal: Centro Gráfico, 1988.

BRASIL. Projeto escola viva: garantindo o acesso e permanência de todos os alunos na escola - alunos com necessidades educacionais especiais. v. 6. Brasília: MEC/SEESP, 2000.

CARVALHO, R. E. Removendo barreiras para a aprendizagem: educação inclusiva. 7. ed. Porto Alegre: Mediação, 2007.

FOUCAULT. M. A hermenêutica do sujeito. curso dado no Cóllège de France (1981-1982). Tradução de M. A. Fonseca e S. T. Muchail. São Paulo: Martins Fontes, 2006.

GADOTTI, M. Educar para outro mundo possível. São Paulo: Publisher Brasil, 2007.

MANTOAN, M. T. E. Inclusão escolar: o que é? por quê? como fazer? São Paulo: Summus, 2015.

MARCONI, M. A.; LAKATOS, E. M. Metodologia do trabalho científico: procedimentos básicos, pesquisa bibliográfica, projeto e relatório, publicações e trabalhos científicos. 7. ed. 6. reimp. São Paulo: Atlas, 2011.

MAZZOTTA, M. J. S. Educação especial no Brasil: história e políticas públicas. São Paulo: Cortez, 1996.

MINAYO, M. C. S. Pesquisa social: teoria, método e criatividade. 24. ed. Petrópolis: Vozes, 1994.

PARANÁ. Diretrizes curriculares da educação especial para a construção de currículos inclusivos. Curitiba: SEED, 2006. Acesso em: 12 jan. 2016.

RODRIGUES, D. (Org.). Inclusão e educação: Doze olhares sobre a educação inclusiva. São Paulo: Summus, 2006.

SASSAKI, R. K. Inclusão: construindo uma sociedade para todos. 8. ed. Rio de Janeiro: WVA, 2010. 